\title{
Rational choice of cholinesterase inhibitor for the treatment of Alzheimer's disease in Canada: a comparative economic analysis Jaime Caro*1,2, Denis Getsios ${ }^{3}$, Kristen Migliaccio-Walle ${ }^{1}$, Jack Ishak ${ }^{4}$, Wissam El-Hadi ${ }^{4}$ and for the AHEAD Study Group
}

Address: ${ }^{1}$ Caro Research Institute, Concord, MA 01742, USA, 2Division of General Internal Medicine, Royal Victoria Hospital, McGill University, Montreal, Quebec, Canada, ${ }^{3}$ Caro Research Institute, Hammonds Plains, Nova Scotia, B4B 1N6, Canada and ${ }^{4}$ Caro Research Institute, Dorval, Quebec, H9S 5J9, Canada

Email: Jaime Caro* - jcaro@caroresearch.com; Denis Getsios - dgetsios@caroresearch.com; Kristen Migliaccio-Walle - kmw@caroresearch.com; Jack Ishak - jishak@caroresearch.com; Wissam El-Hadi - welhadi@caroresearch.com; for the AHEAD Study Group -

* Corresponding author

Published: 15 December 2003

BMC Geriatrics 2003, 3:6
Received: 17 July 2003

Accepted: 15 December 2003

This article is available from: http://www.biomedcentral.com/I47I-23/8/3/6

(C) 2003 Caro et al; licensee BioMed Central Ltd. This is an Open Access article: verbatim copying and redistribution of this article are permitted in all media for any purpose, provided this notice is preserved along with the article's original URL.

\begin{abstract}
Background: Cholinesterase inhibitors, such as galantamine, donepezil and rivastigmine are approved for symptomatic treatment of Alzheimer's Disease (AD) in Canada. In making choices amongst these drugs, one should consider their clinical merits and their economic implications.

Methods: Each drug's short-term efficacy was estimated based on independent Cochrane reviews of the clinical trials. Long-term clinical and economic outcomes were estimated using the Assessment of Health Economics in Alzheimer's Disease (AHEAD) model.
\end{abstract}

Results: While all treatments reduced the need for full-time care, only galantamine and donepezil $10 \mathrm{mg}$ reduced the overall management costs of $A D$ patients. The somewhat greater cognitive effect provided over six months by galantamine leads to the longest estimated delay before full-time care is required and, consequently to lower overall costs, with savings estimated at between $\$ 323$ and $\$ 4,246$.

Conclusion: Although there is uncertainty in estimated results, the best information currently available suggests that the first choice for treatment of $A D$ should be galantamine. These results should be interpreted with caution, however, as results are not based on direct comparisons among the drugs and the differences emerging from meta-analyses of the trials are relatively small.

\section{Background}

The number of Canadians with Alzheimer's disease (AD) is expected to rise to over half a million by 2031 [1], and the costs of caring for these patients have been shown to be heavily dependent on disease severity $[2,3]$, with a recent estimate of $\$ 9,451$ (1996 Canadian dollars) per year for patients with mild $\mathrm{AD}$ to $\$ 36,794$ per year for patients with severe $\mathrm{AD}[3]$.
Although the adoption of cholinesterase inhibitors for the treatment of $\mathrm{AD}$ has not met with unconditional endorsement in Canada $[4,5]$, this was the only class of antidementia drugs recommended by the Canadian Consensus Conference on Dementia [6] and is becoming the standard of care. It is hoped that the short-term benefits observed in clinical trials lasting a few months [7-9] will translate to slower decline over the subsequent years. 
No studies have yet fully documented the long-term economic implications of treatment with these drugs, but four [10-13] have estimated what they might be in Canada using models of the course of the illness. Similar analyses have also been carried out for other countries [1421]. Although each of the Canadian analyses predicted delayed disease progression and associated savings, the lack of a common methodology and contrasts with other active treatments mean that the results are not directly comparable and, thus, do not help in making choices among the drugs.

To inform therapeutic decisions, we undertook a comparison of the three cholinesterase inhibitors approved for use in Canada: donepezil, rivastigmine and galantamine. We sought to remove extraneous effects due to disparate modeling approaches by using a common, published and validated, analytic framework: the Assessment of Health Economics in Alzheimer's Disease (AHEAD) model [22]. To ensure balanced estimates of the efficacy of these drugs, particularly given our source of funding, we based our calculations on the independent reviews published by the Cochrane Collaboration [23-25].

\section{Methods \\ The AHEAD Model}

The AHEAD model simulates the course of AD according to the patient's characteristics at a given point in time $[13,22]$. This is done by forecasting the time until each patient with $\mathrm{AD}$ requires full-time care (FTC) - the consistent requirement for a significant amount of caregiving and supervision for the greater part of the day, regardless of the locus of care and who the caregiver is. These forecasts are derived by estimating the failure-time curves that result from the corresponding time-dependent hazards. The hazards are calculated using equations that depend on the presence of extrapyramidal symptoms (EPS), the presence of psychotic symptoms, age at onset, duration of illness and cognitive status. The model also forecasts survival, which depends on sex, EPS, duration of illness and cognitive status. The required equations were derived from published long-term follow up data of patients with AD [26].

The model considers four states: 1 ) not yet requiring FTC (pre-FTC), 2) requiring FTC but still living in the community (FTC community), 3) requiring FTC and institutionalized (FTC institution), or 4) dead. The model uses individual patient data as inputs into the predictive equations, and the individual results are then aggregated into an overall forecast for the entire cohort. Comparisons between treatment scenarios are achieved by re-computing the failure-time curves for the same patients under each treatment scenario.
The cognitive portion of the Alzheimer Disease Assessment Scale (ADAS-cog) [27] is used as the measure of cognition in this model as cognitive outcomes of trials are typically reported using this measure. Cognitive status after six months $\left(\mathrm{C}_{6}\right)$ in the absence of pharmacologic treatment is forecast using a regression equation based on baseline cognitive status $\left(\mathrm{C}_{0}\right)$. The equation, derived from patient-level data on untreated participants in three clinical trials [28-30] was $\mathrm{C}_{6}=-0.54+1.10 \mathrm{C}_{0}$ (the $95 \%$ confidence intervals for the coefficients were -1.94 to 0.97 for the intercept term, and 1.05 to 1.15 for the slope term). An increase in the score reflects deterioration in cognitive functioning.

Along with the duration of FTC and economic outcomes, the model calculates quality adjusted life years (QALY) remaining by assigning quality "weights" to each state. Values of 0.603 for pre-FTC, 0.338 for FTC regardless of location of care, and 0 for death were derived from published data [31]. A single value was used for FTC as the study on which quality weights were based found that setting of care did not have an independent effect on outcomes [31].

If one treatment is estimated to increase health benefits but also the costs relative to the next most effective treatment, the model calculates the incremental cost-effectiveness ratio in terms of the net cost per QALY gained (both discounted). Pair-wise comparisons, even for treatments otherwise dominated, are also reported here since these may be relevant in settings where the dominant treatment cannot be used.

Results are forecast over ten years from the start of treatment because by that time all survivors require FTC. A rate of $3 \%$ per annum was used to discount costs and health benefits occurring after year one.

\section{Population for Analyses}

To provide a common population of patients for these analyses, the clinical and demographic characteristics of participants in a recent clinical trial [30] were used. Among these 918 patients, who should be broadly representative of those for whom the drugs are indicated, $64.9 \%$ were female and the mean age was 77.2 years. ADAS-Cog scores ranged from 10 to 62 , with the mean ADAS-cog score at baseline being 28.9 and the first and third quartiles of the distribution being 21 and 36, respectively. Psychotic symptoms were exhibited in $32.4 \%$ of the patient population, $7.5 \%$ had EPS, $8.9 \%$ had early onset of disease, and the mean duration of illness was just over four years. In the absence of pharmacologic treatment, it was estimated that after six months, the average ADAS-cog score would deteriorate to 31.3 . 
Table I: Cochrane review data used as the basis for this analysis

\begin{tabular}{ccccccc}
\hline & \multicolumn{2}{c}{ Donepezil } & \multicolumn{2}{c}{ Rivastigmine } & \multicolumn{2}{c}{ Galantamine } \\
\hline Daily dose & $5 \mathrm{mg}$ & $10 \mathrm{mg}$ & $1-4 \mathrm{mg}$ & $6-12 \mathrm{mg}$ & $16 \mathrm{mg}$ & $24 \mathrm{mg}$ \\
Efficacy* & -1.86 & -2.90 & -0.84 & -2.09 & -3.10 & -3.29 \\
$95 \% \mathrm{Cl}$ & $-2.60,-1.11$ & $-3.65,-2.16$ & $-1.48,-0.19$ & $-2.65,-1.54$ & $-4.13,-2.07$ & $-3.92,-2.65$ \\
Beta ${ }^{9}$ & -0.071 & -0.106 & -0.036 & -0.091 & -0.105 & -0.124 \\
$95 \% \mathrm{Cl}$ & $-0.099,-0.042$ & $-0.133,-0.079$ & $-0.067,-0.008$ & $-0.115,-0.067$ & $-0.14-0.070$ & $-0.147,-0.100$ \\
Withdrawal ${ }^{\ddagger}$ & 1.02 & 1.36 & 1.01 & 1.95 & 1.34 & 1.51 \\
$95 \% \mathrm{Cl}$ & $0.78,1.33$ & $1.10,1.70$ & $0.80,1.27$ & $1.65,2.32$ & $0.95,1.89$ & $1.23,1.87$ \\
\hline
\end{tabular}

$*$ measured in terms of the weighted difference in mean cognitive change on the ADAS-cog comparing treatment to placebo $\dagger$ coefficient for variable effect analysis calculated as the efficacy divided by the mean baseline score $\ddagger$ relative risk of withdrawing from treatment, compared to placebo patients

\section{Treatment Efficacy}

Computations for each treatment were based on the cognitive effects reported in the Cochrane reviews - formal meta-analyses of the randomized clinical trials assessing efficacy and safety of these drugs. For each drug and dose, the reviews reported point estimates and 95\% confidence intervals (CI) for the weighted difference in mean cognitive change comparing the treatment to placebo using intention-to-treat analysis with last observation carried forward (LOCF) methods used for patients dropping out of the trial (Table 1). While it is possible that the LOCF method may slightly overestimate the cognitive effects of treatment if withdrawals from the trial are higher with treatment than without (as patients cognition, on average, should decline between the time of withdrawal and the end of the study), these were the only data available for all three active treatments and the same methods were used for all.

These estimates were used to determine the change in cognition expected with each treatment and dose over six months for each patient in the model population. Two approaches were taken to make these predictions. For the main analyses, the most direct approach was used: the Cochrane estimated mean difference from placebo $(\Delta \mathrm{C})$ was applied to the intercept term in the regression equation that describes progression without treatment: $\mathrm{C}_{6}=(-$ $0.54+\Delta \mathrm{C})+1.10 \mathrm{C}_{0}$. This implies that treatment has a constant absolute effect on cognition, regardless of baseline ADAS-cog - thus termed the 'constant effect' analysis.

To consider possible dependency of the treatment effect on the baseline disease severity [32,33], a second, 'variable effect", approach was used in sensitivity analyses. For this approach, a term was added to the regression equation reflecting the interaction between treatment $(\mathrm{T})$ and baseline ADAS-cog score: $C_{6}=-0.54+1.10 C_{0}+\beta \cdot T \cdot C_{0}$. The coefficient $\beta$ was estimated for each treatment by solving the equation at the mean baseline ADAS-cog scores reported for each treatment arm in the trials [28-30], [3436]: $\beta=\Delta \mathrm{C} / \bar{C}_{0}$ (Table 1 ).

In both the constant and variable effect analyses, the treatment effect was applied only to patients who were predicted to complete the first six months of therapy. For those predicted to withdraw from therapy, the rates of cognitive change expected without treatment were applied. The likelihood of completing the first six months of treatment was predicted for each patient by adjusting the base withdrawal rate incorporated in AHEAD according to a treatment-specific factor derived from the Cochrane reviews by calculating the ratio of treatment to placebo withdrawals (Table 1 ). For example, if treatment were associated with a relative risk of withdrawing equal to 2 , and the base withdrawal risk for a patient were $10 \%$, then with treatment, the withdrawal risk would be $20 \%$ (2 $\times 10 \%)$. The overall base withdrawal rate in AHEAD was $16 \%$.

Although there is evidence that these drugs may have an impact on psychotic symptoms [37], this aspect was not included in these analyses because those data were not reported in the Cochrane reviews for all treatments.

Evidence that treatment affects survival is not yet available so mortality was assumed to be equal for all therapeutic options. This equivalence was ensured by calculating mortality with all three treatments using the ADAS-cog scores had the patients remained untreated.

\section{Costs}

Costs are reported in 2001 Canadian dollars and are determined from the perspective somewhat broader than that of a comprehensive payer. For example, informal costs such as in-home personal care were included. Costs were estimated based primarily on resource use data from the clinical assessment portion of a follow-up survey of the Canadian Study of Health and Aging [38] and unit costs 
Table 2: Inputs for the multivariate sensitivity analyses

\begin{tabular}{lccc}
\hline Parameter & Type & Mid-Point & Range \\
\hline Pre-FTC cost & Triangular & $\$ 432$ & $\$ 279-\$ 584$ \\
FTC in Community cost & Triangular & $\$ 903$ & $\$ 584-\$ 1,222$ \\
FTC in Institution cost & Triangular & $\$ 3,931$ & $\$ 2,543-\$ 5,319$ \\
$\%$ FTC in Institution & Triangular & $73.5 \%$ & $47 \%-100.0 \%$ \\
Cognitive effect & Normal & See Table I for means and ranges \\
Withdrawal Risk & Normal $\left.\right|^{\dagger}$ of Log RR & See Table I for means and ranges \\
\hline
\end{tabular}

$\dagger$ all normal distributions were bounded at their two standard deviations $\ddagger$ relative risk of withdrawing from treatment, compared to untreated patients

from the province of Quebec using methods described elsewhere [13]. The estimates were $\$ 432$ per patient per month before FTC is required, $\$ 903$ monthly for FTC in the community and \$3,931 for a month of FTC in an institution. Based on published data, it is expected that that almost three-quarters $(73.5 \%)$ of patients requiring FTC will be institutionalized $[3,13]$. No event cost was assigned to the transition to FTC or to death. The daily cost of each cholinesterase inhibitor was set at $\$ 4.59$. Daily treatment cost was independent of dose, reflecting current pricing practices for cholinesterase inhibitors in Canada. Patients predicted to discontinue treatment were assumed to consume three months of drug. It was conservatively assumed that to maintain the cognitive benefit obtained, all those who do not withdraw in the first six months, require continued treatment until FTC is needed. Once this happens, pharmacologic treatment was assumed to end for all patients. Treatment discontinuation prior to needing FTC was not considered, although one might expect that in addition to no longer incurring treatment costs, benefits attained through treatment prior to discontinuation may be lost over time.

\section{Sensitivity Analyses}

Sensitivity analyses were performed on key inputs and assumptions. To reflect the uncertainty in the relative cognitive effect of each treatment, univariate sensitivity analyses were run using the upper and lower 95\% confidence interval bounds for each drug's treatment effect. Health utility and cost inputs were varied and a potential survival benefit based on the cognitive effect was explored. Sensitivity analyses were also conducted assuming lower discontinuation rates, as the Cochrane reviews present evidence of modified dose-escalation regimens for each of the three therapies leading to significantly fewer drop-outs over the trial periods. Finally, all analyses were rerun using discount rates of $0 \%, 5 \%$ and $10 \%$.

Apart from univariate analyses of each factor, multivariate probabilistic analyses were also carried out. The ranges over which each factor was changed in the multivariate analyses are displayed in Table 2.

\section{Results}

With no pharmacologic treatment, the patients modeled are expected to survive, on average, an additional 60.3 months and to require FTC after an estimated 38.4 months. The average total cost of caring for these patients over the modeling period is $\$ 84,869 \quad(\$ 76,806$ discounted).

\section{Main Analysis}

In the constant effect analysis, all treatments reduce the time FTC is required relative to no treatment, but only the higher dose of donepezil and both doses of galantamine reduce costs (Table 3 ). As these three treatment options also provide greater effects, they dominate the others (i.e., have greater health effects and lead to lower overall costs). Both doses of galantamine also dominate the higher dose of donepezil. The only cost-effectiveness scenario amongst active treatments exists with donepezil $5 \mathrm{mg}$, which has a superior health effect compared to rivastigmine 6-12 mg, but is more expensive, with incremental benefits attained at a cost of over $\$ 150,000$ per QALY gained.

\section{Sensitivity Analyses \\ Variable Effect}

In the variable effect analyses, the most notable change is that the lower dose of galantamine was no longer dominant over donepezil $10 \mathrm{mg}$ : now a nominal reduction of FTC need $(0.1 \%)$ is obtained at an incremental cost of $\$ 3$ per patient ( $\$ 13,338$ per QALY gained).

\section{ADAS-Cog change}

When the upper limits of the $95 \%$ confidence interval of the weighted difference in mean ADAS-cog change are used, the relative positions of the treatments do not change, but when the lower limits are used, the higher dose of donepezil dominates the lower one of galantamine. This results from the tighter interval around the 
Table 3: Principle outcomes of the constant effect analyses*

\begin{tabular}{|c|c|c|c|c|c|c|}
\hline \multirow{3}{*}{ Treatment } & \multicolumn{6}{|c|}{ Comparator } \\
\hline & \multirow[t]{2}{*}{ No drug treatment } & \multicolumn{2}{|c|}{ Rivastigmine } & \multicolumn{2}{|c|}{ Donepezil } & \multirow{2}{*}{$\begin{array}{c}\text { Galantamine } \\
16 \mathrm{mg}\end{array}$} \\
\hline & & $\mathrm{I-4} \mathrm{mg}$ & $6-12 \mathrm{mg}$ & $5 \mathrm{mg}$ & $10 \mathrm{mg}$ & \\
\hline \multicolumn{7}{|l|}{ Rivastigmine } \\
\hline $\mathrm{I}-4 \mathrm{mg}$ & $3.0 \% * * * \$ 2,880+\$ 224,222 \pi$ & & & & & \\
\hline $6-12 \mathrm{mg}$ & $5.8 \% \$ 514 \$ 36,161$ & $3.0 \%-\$ 2,370$ Dominant & & & & \\
\hline \multicolumn{7}{|l|}{ Donepezil } \\
\hline $5 \mathrm{mg}$ & $6.6 \% \$ 1,032 \$ 36,161$ & 3.7\% - $\$ 1,849$ Dominant & $0.8 \% \$ 522 \$ 158,875$ & & & \\
\hline $10 \mathrm{mg}$ & $9.5 \%-\$ 81$ I Dominant & $6.7 \%-\$ 3,692$ Dominant & $3.9 \%-\$ 1,321$ Dominant & 3.1\% - $\$ 1,843$ Dominant & & \\
\hline \multicolumn{7}{|l|}{ Galantamine } \\
\hline $16 \mathrm{mg}$ & I0.2\% -\$1,I34 Dominant & $7.5 \%-\$ 4,015$ Dominant & $4.6 \%-\$ 1,644$ Dominant & $3.9 \%-\$ 2,166$ Dominant & $0.8 \%-\$ 323$ Dominant & \\
\hline $24 \mathrm{mg}$ & $10.3 \%-\$ 1,366$ Dominant & $7.6 \%-\$ 4,246$ Dominant & $4.7 \%-\$ 1,876$ Dominant & $4.0 \%-\$ 2,398$ Dominant & $0.9 \%-\$ 555$ Dominant & $0.1 \%-\$ 232$ Dominant \\
\hline
\end{tabular}

* for each drug treatment in the rows the comparison is made relative to the approach in the column ** percent reduction in time spent requiring FTC + net costs $\pi$ incremental cost per QALY gained

donepezil estimate (Sensitivity analyses reported in the following sections were also carried out for the variable effect analyses. Results available from the authors.).

\section{Treatment Withdrawal}

The confidence intervals of the withdrawal adjustment factors for the lower doses of all three cholinesterase inhibitors included a value of one (i.e., withdrawal no different than with placebo), and there is some evidence that slower titration regimens might result in lower discontinuation rates even for the higher doses of these drugs. An analysis was therefore undertaken assuming that the withdrawal factor was one for all treatments. The only resulting change in position of the treatments was that higher dose rivastigmine dominated the lower dose of donepezil under these conditions.

\section{Mortality}

Although there is no evidence to indicate that cholinesterase inhibitors improve survival, if the cognitive benefits are allowed to translate to mortality reductions, all treatments are predicted to increase costs relative to no treatment because the additional survival incurs further costs. This does not affect, however, the position of the active treatments relative to one another.

\section{FTC Costs}

Changes in this parameter affect the results relative to no treatment, but not the comparisons among treatment options.

\section{Health Utilities}

Changes in health utility estimates of $25 \%$ in either direction had no appreciable impact on the comparisons among cholinesterase inhibitors.

\section{Discount Rate}

Alternative discount rates also had only a small influence on overall results, and did not influence the relative ranking of active treatments. For example, galantamine 24 mg resulted in net savings ranging from $\$ 249$ to $\$ 4,705$ if no discounting were applied. If a $10 \%$ rate were used, savings, although lower, were still attained in all cases, ranging from $\$ 201$ to $\$ 3,414$.

\section{Multivariate Analysis}

The results of the multivariate sensitivity analyses largely confirm the main ones. The higher dose of rivastigmine is always dominated by the higher dose of galantamine and nearly always $(96.1 \%)$ by the lower dose of galantamine. The higher dose of donepezil is only dominated in about half the scenarios $(55.6 \%)$ with respect to the lower dose of galantamine, and is dominated by the higher dose of galantamine most of the time $(69.4 \%)$.

\section{Discussion}

The results of these analyses, which incorporate the best currently available information, suggest that galantamine should be the first choice for treatment of patients with $\mathrm{AD}$. Using the AHEAD model to extend independently published short-term efficacy estimates, galantamine is predicted to lead to a somewhat longer delay of the need for FTC and ultimately lower costs, thus dominating other treatment options. The second best choice appears to be donepezil.

These results need to be placed in context. To date, adequate direct comparisons of these drugs in clinical trials are lacking, and the Cochrane meta-analyses show relatively small differences among the treatments. Furthermore, it is impossible to ensure that differences among the study populations and trial protocols are fully accounted for, even in the variable effect analysis. It 
should also be kept in mind that treatment effects for all drugs were based on populations enrolled in clinical trials, which may not be representative of the $\mathrm{AD}$ population in Canada as a whole. Until long-term data become available for patients treated in the community, however, it is difficult to determine how much different the clinical effectiveness and tolerability of these drugs will be in actual practice relative to a clinical trial setting. Finally, long-term forecasts are made based on the results of trials that lasted only six months. Longer-term data are emerging [39-44], but these are even less comparative as most are open-label extensions of trials where most patients were switched to active treatment regardless of original assignment.

Despite these sources of uncertainty, the results are maintained over most sensitivity analyses. In the multivariate probabilistic sensitivity analyses, galantamine remained dominant in the vast majority of scenarios.

Other factors not taken into account in this analysis should also be considered as data become available. Of note, these analyses limit the effect of these drugs to cognition. There is growing evidence that aspects other than cognition may be improved by treatment $[30,37,45,46]$. For example, in one double-blind placebo-controlled trial that measured behavioral symptoms [30], patients randomized to either galantamine $16 \mathrm{mg}$ or $24 \mathrm{mg}$ showed significant behavioral benefits over placebo-treated patients. This aspect of treatment was not included in the analysis, however, as appropriate data from randomized trials were not available for all three cholinesterase inhibitors under evaluation.

Caregiver burden has also not been considered [47-49] in this analysis. In Canada, the most recent estimate of caregiving costs places these at between $\$ 400$ and $\$ 700$ per patient, per month, depending on the stage of the disease [3] and the recent Canadian Consensus Conference on Dementia acknowledged the significant burden placed on caregivers of the demented elderly [6]. Data that would allow inclusion of caregiver burden and its attendant costs are beginning to appear. For example, the effects of galantamine on caregiver time were assessed in a 6-month randomized, placebo-controlled trial [50]. Caregivers of patients on galantamine spent less time supervising patients than caregivers of patients on placebo (by between 82 and 98 minutes per day). Caregivers of treated patients also spent between 38 and 61 minutes less per day assisting patients with activities of daily living. Inclusion of this aspect would add to the completeness of the analysis, and likely accentuate current results. As comparable data for donepezil and rivastigmine are currently lacking, however, a conservative approach was taken and caregiver burden was left out of the analysis.
It is also worth noting that individuals may respond to one drug better than another in ways not reflected by calculations based on the average effects in a population, such as those used in this analysis. Thus, treatment should be tailored to each patient, with careful monitoring of response and tolerability dictating the final treatment course.

\section{Conclusions}

With the number of Canadians with $\mathrm{AD}$ increasing and health care resources already stretched, it is becoming increasingly important to evaluate therapeutic alternatives for these patients to provide a rational basis for treatment decisions. These analyses indicate that galantamine should be the first choice for treatment of $A D$, but it must be conceded that the information is less than optimal and differences emerging from meta-analyses of the clinical trials are relatively small. Further comparative experience over the next several years should provide a more definitive assessment of the long-term health and economic consequences of these drugs. Large-scale head-tohead clinical trials between the available cholinesterase inhibitors would provide the evidence base for a more authoritative conclusion on the relative effectiveness and cost-effectiveness of these drugs.

Finally, as new treatments emerge, these will also need to be assessed, even before complete data are available. The AHEAD model provides a framework for these assessments.

\section{Competing interests}

This work was supported in part by a grant from JanssenOrtho to Caro Research. Janssen-Ortho collaborated in helping set the specifications for the model of this work but had no role in methodological decisions nor interpretation of results. They were also allowed to review and comment on this manuscript but were explicitly forbidden from exerting any editorial control. The authors are employees of Caro Research, and one (JaimeCaro) is a shareholder. Caro Research has also received grants for other, unrelated, research from Pfizer and Novartis, the makers of products potentially affected by this work.

\section{Authors' contributions}

All authors contributed substantially to the conception and design of this study, analysis and interpretation, and to the writing of the manuscript. All authors have read and approved the final version of the manuscript.

\section{Acknowledgements \\ None.}




\section{References}

I. Canadian Study of Health and Aging Working Group: Canadian Study of Health and Aging: study methods and prevalence of dementia. CMAJ 1994, I50:899-913.

2. Ostbye $\mathrm{T}$, Crosse $\mathrm{E}$ : Net economic costs of dementia in Canada. CMAJ 1994, I 5 I: I457-I464.

3. Hux MJ, O'Brien BJ, Iskedjian M, Goeree R, Gagnon M, Gauthier S: Relation between severity of Alzheimer's disease and costs of caring. CMAJ 1998, I 59:457-465.

4. Pryse-Phillips W, Sternberg S, Rochon P, Naglie G, Strong H, Feightner J: The use of medications for cognitive enhancement. Can J Neurol Sci 200I, 28(suppl I):SI08-SII4.

5. Huserau D, Wolfson C, Shukla VK: Drug treatments for Alzheimer's disease efficacy, outcome measurements and costeffectiveness. Ottawa: Canadian Coordinating Office of Health Technology Assessment (CCOHTA) 200I. Technology Overview no.4

6. Patterson CJS, Gauthier S, Bergman H, Cohen CA, Feightner JW, Feldman $\mathrm{H}$, Hogan DB: The recognition, assessment and management of dementing disorders: conclusions from the Canadian Consensus Conference on Dementia. CMAJ 1999, I 60(suppl 2):SI-SI5.

7. Doody M, Lamb HM, Donepezil : A review of its use in Alzheimer's disease. Drugs Aging 2000, 16:199-226.

8. Spencer CM, Noble S, Rivastigmine : A review of its use in Alzheimer's disease. Drugs Aging |998, |3:39|-4| I.

9. Scott LJ, Goa KL, Galantamine : A review of its use in Alzheimer's disease. Drugs 2000, 60:1095-II 22.

10. O'Brien BJ, Goeree R, Hux M, Iskedjian M, Blackhouse G, Gagnon M, Gauthier S: Economic evaluation of donepezil for the treatment of Alzheimer's disease in Canada. J Am Geriatr Soc 1999, 47:570-578.

II. Hauber AB, Gnanasakthy A, Mauskopf JA: Savings in the cost of caring for patients with Alzheimer's disease in Canada: an analysis of treatment with rivastigmine. Clin Ther 2000, 22:439-45I.

12. Baladi J-F, Bailey PAB, Black S, Bouchard RW, Farcnik KD, Gauthier S, Kertesz A, Mohr E, Robillard A: Rivastigmine for Alzheimer's disease: Canadian interpretation of intermediate outcome measures and cost implications. Clin Ther 2000, I 2: I549-I56 I.

13. Getsios D, Caro J, Caro G, Ishak J, for the AHEAD Study Group: Assessment of health economics in Alzheimer's disease (AHEAD): galantamine treatment in Canada. Neurology 200 I, 57:972-978.

14. Jönsson L, Lindgren P, Wimo A, Jönsson B, Winblad B: The costeffectiveness of donepezil therapy in Swedish patients with Alzheimer's disease: a Markov model. Clin Ther 1999, 21:1230-1240.

15. Neumann PJ, Hermann RC, Kuntz KM, Araki SS, Duff SB, Leon J, Berenbaum PA, Goldman PA, Williams LW, Weinstein MC: Cost effectiveness of donepezil in the treatment of mild to moderate Alzheimer's disease. Neurology 1999, 52: I |38-I |45.

16. Stewart A, Phillips R, Dempsey G: Pharmacotherapy for people with Alzheimer's disease: a Markov-cycle evaluation of five years' therapy using donepezil. Int $J$ Geriatr Psychiatry 1998:445-453.

17. Ikeda S, Yamada Y, Ikegami N: Economic evaluation of donepezil treatment for Alzheimer's disease in Japan. Dement Geriatr Cogn Disord 2002, 13:33-39.

18. Stein K: Donepezil in the treatment of mild to moderate senile dementia of Alzheimer type (SDAT). Bristol: NHS Executive South and West Development and Evaluation Committee Report No.69; 1997.

19. Fenn P, Gray A: Estimating long-term cost savings from treatment of Alzheimer's disease: a modeling approach. Pharmacoeconomics 1999, 16:165-174.

20. Hauber AG, Gnanasakthy A, Snyder EH, Bala MV, Richter A Mauskopf JA: Potential savings in the cost of caring for Alzheimer's disease: treatment with rivastigmine. Pharmacoeconomics 2000, I 7:351-360.

21. Stein K: Rivastigmine (Exelon) in the treatment of senile dementia of Alzheimer type (SDAT). Bristol: NHS Executive South and West Development and Evaluation Committee Report No.89; 1998.

22. Caro J], Getsios D, Migliaccio-Walle K, Raggio G, Ward A: Assessment of health economics in Alzheimer's disease (AHEAD) based on need for full-time care. Neurology 200I, 57:964-97I.
23. Birks JS, Melzer D, Beppu H: Donepezil for mild and moderate Alzheimer's disease (Cochrane Review). In: The Cochrane Library Issue 4 Oxford: Update Software; 2000.

24. Birks JS, Grimley Evans J, lakovidou V, Tsolaki M: Rivastigmine for Alzheimer's disease (Cochrane Review). In: The Cochrane Library Issue 4 Oxford: Update Software; 2000.

25. Olin J, Schneider L: Galantamine for Alzheimer's disease (Cochrane Review). In: The Cochrane Library Issue I Oxford: Update Software; 200I.

26. Stern Y, Tang M-X, Albert MS, Brandt J, Jacobs DM, Bell K, Marder K, Sano M, Devanand D, Albert SM, Bylsma F, Tsai WY: Predicting time to nursing home care and death in individuals with Alzheimer's disease. J Am Med Assoc 1997, 277:806-8I2.

27. Rosen WG, Mohs RC, Davis KL: A new rating scale for Alzheimer's disease. Am J Psychiatry 1984, I 4 I: | 356- | 364.

28. Raskind MA, Peskind ER, Wessel T, Yuan W, and the Galantamine USA-I Study Group: Galantamine in AD. A 6-month randomized, placebo-controlled trial with a 6-month extension. Neurology 2000, 54:226I-2268.

29. Wilcock GK, Lilienfield S, Gaens E, on behalf of the Galantamine International-I study Group: Efficacy and safety of galantamine in patients with mild to moderate Alzheimer's disease: multicentre randomized controlled trial. BM] 2000, $32 \mathrm{I}: \mathrm{I}-7$.

30. Tariot PN, Solomon PR, Morris JC, Kershaw P, Lilienfeld S, Ding C: A 5-month randomized, placebo-controlled trial of galantamine in AD. Neurology 2000, 54:2269-2276.

31. Neumann PJ, Kuntz KM, Leon J, Araki SS, Hermann RC, Hsu M-A, Weinstein MC: Health utilities in Alzheimer's disease: a crosssectional study of patients and caregivers. Med Care 1999, 37:27-32.

32. Schneider LS, Anand R, Farlow MR: Systematic review of the efficacy of rivastigmine for patients with Alzheimer's disease. Int J Geriatr Psychopharmacol 1998, I (suppl I):S26-S34.

33. Lilienfield S, Parys W: Galantamine: additional benefits to patients with Alzheimer's disease. Dement Geriatr Cogn Disord 2000, I I (suppl I): I9-27

34. Rogers SL, Farlow MR, Doody RS, Mohs R, Friedhoff LT, and the Donepezil Study Group: A 24-week, double-blind, placebo-controlled trial of donepezil in patients with Alzheimer's disease. Neurology 1998, 50:136-|45.

35. Rösler M, Anand R, Cicin-Sain A, Gauthier S, Agid Y, Dal-Bianco P, Stahelin HB, Hartman R, Gharabawi M: Efficacy and safety of rivastigmine in patients with Alzheimer's disease: international randomised controlled trial. BMJ 1999, 3 I 8:633-640.

36. Corey-Bloom J, Anand R, Veach J, for the ENA 7I3 B352 Study Group: A randomized trial evaluating the efficacy and safety of ENA 713 (rivastigmine tartrate), a new acetylcholinesterase inhibitor, in patients with mild to moderately severe Alzheimer's disease. Int J Geriatr Psychopharmacol 1998, I:55-65.

37. Cummings JL: Cholinesterase inhibitors: a new class of psychotropic compounds. Am J Psychiatry 2000, I 57: I- I5.

38. University of Ottawa, Faculty of Medicine: The Canadian Study of Health and Aging Home Page. [http://www.uottawa.ca/aca demic/med/epid/csha.html].

39. Rogers SL, Doody RS, Pratt RD, leni JR: Long-term efficacy and safety of donepezil in the treatment of Alzheimer's disease: final analysis of a US multicentre open-label study. Eur Neuropsychopharmacol 2000, 10:195-203.

40. Doody RS, Geldmacher DS, Gordon B, Perdomo CA, Pratt RD, for the Donepezil Study Group: Open-label, multicenter, Phase 3 Extension Study of the safety and efficacy of donepezil in patients with Alzheimer's disease. Arch Neurol 200I, 58:427-433.

4I. Doody RS, Dunn JK, Clark CM, Farlow M, Foster NL, Liao T, Gonzales N, Lai E, Massman P: Chronic donepezil treatment is associated with slowed cognitive decline in Alzheimer's disease. Dement Geriatr Cogn Disord 200 I, I 2:295-300.

42. Winblad B, Engedal K, Soininen H, Verhey F, Waldemar G, Wimo A Wetterholm AL, Zhang R, Haglund A, Subbiah P, Donepezil Nordic Study Group: A I-year, randomized, placebo-controlled study of donepezil in patients with mild to moderate AD. Neurology 2001, 57:489-495.

43. Mohs RC, Doody RS, Morris JC, leni JR, Rogers SL, Perdomo CA, Pratt RD, "3 I2" Study Group: A I-year, placebo-controlled preservation of function survival study of donepezil in AD patients. Neurology 200I, 57:48I-488. 
44. Farlow M, Anand R, Messina J Jr, Hartman R, Veach J: A 52-week extension study of the efficacy of rivastigmine in patients with mild to moderately severe Alzheimer's disease. Eur Neurol 2000, 4:236-24I.

45. Thomas A, lacono D, Bonanni L, D'Andreamatteo G, Onofri M: Donepezil, rivastigmine, and vitamin $E$ in Alzheimer's disease: a P300 event-related potentials/neuropsychologic evaluation over 6 months. Clin Neuropharmacol 200I, 24:3I-42.

46. Cummings JL, Donohue JA, Brooks RL: The relationship between donepezil and behavioral disturbances in patients with Alzheimer's disease. J Geriatr Psychiatry 2000, 8: I45- I 40.

47. Max W: Drug treatments for Alzheimer's disease: shifting the burden of care. CNS Drugs 1999, I I:363-372.

48. Busschbach JJV, Brouwer WBF, van der Donk A, Passchier J, Rutten $\mathrm{FFH}$ : An outline for a cost-effectiveness analysis of a drug for patients with Alzheimer's disease. Pharmacoeconomics 1998, | 3:2|-34.

49. Winblad B, Wimo A: Assessing the societal impact of acetylcholinesterase inhibitor therapies. Alzheimer Dis Assoc Disord 1999, I3(suppl 2):S9-S19.

50. Blesa R: Galantamine: therapeutic effects beyond cognition. Dement Geriatr Cogn Disord 2000, I I (suppI I):28-34

\section{Pre-publication history}

The pre-publication history for this paper can be accessed here:

http://www.biomedcentral.com/1471-2318/3/6/prepub

Publish with Bio Med Central and every scientist can read your work free of charge

"BioMed Central will be the most significant development for disseminating the results of biomedical research in our lifetime. "

Sir Paul Nurse, Cancer Research UK

Your research papers will be:

- available free of charge to the entire biomedical community

- peer reviewed and published immediately upon acceptance

- cited in PubMed and archived on PubMed Central

- yours - you keep the copyright 